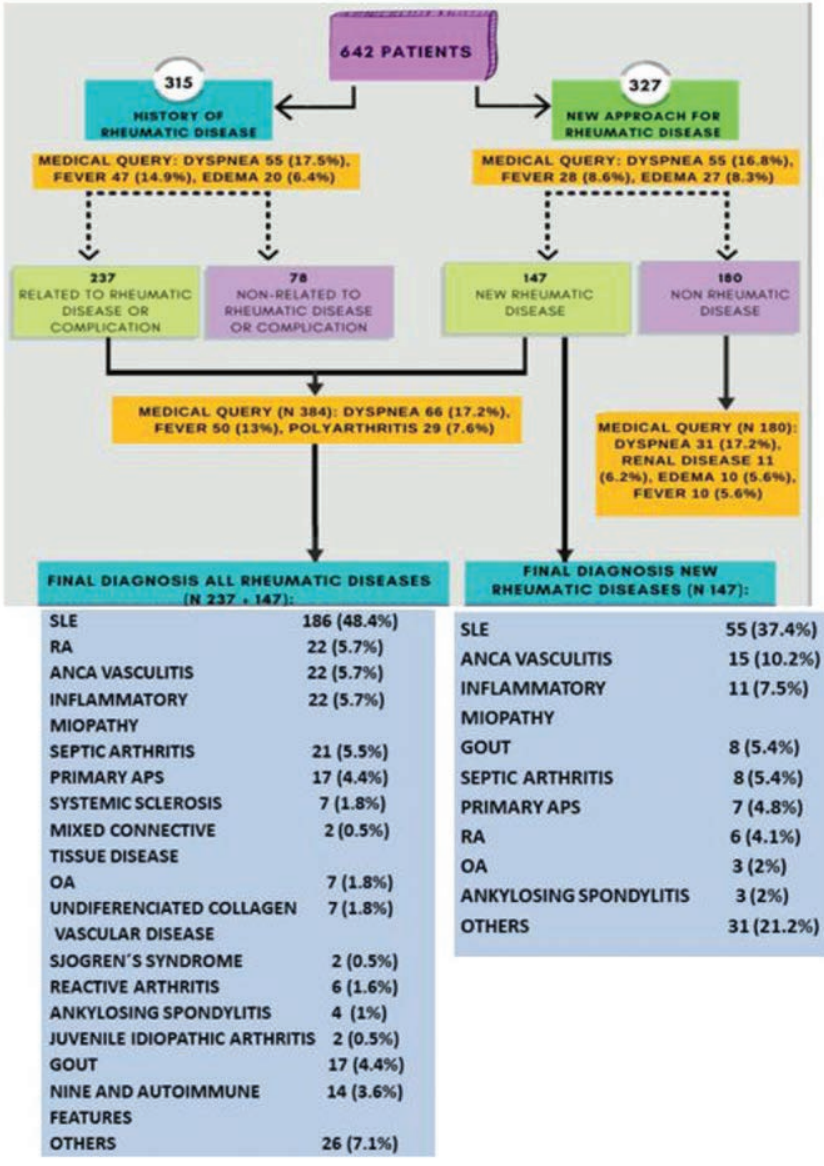

Table 1A. Descriptive analysis of patients receiving a Rheumatology evaluation

\begin{tabular}{llll}
\hline & $\begin{array}{l}\text { Total evaluated } \\
\text { patients }\end{array}$ & $\begin{array}{l}\text { Rheumatic cause of } \\
\text { hospitalization }\end{array}$ & $\begin{array}{l}\text { New rheumatic } \\
\text { disease }\end{array}$ \\
\hline & $\mathrm{n}=642$ & $\mathrm{n}=384$ & $\mathrm{n}=147$ \\
\hline $\begin{array}{l}\text { Age (SD) Mean } \\
\text { Sex }\end{array}$ & $39(25-53)$ & $40(25-53)$ & $40.56(16-89)$ \\
$\begin{array}{l}\text { Female } \\
\text { Median days of } \\
\quad \text { follow up }\end{array}$ & $462(72 \%)$ & $285(74.2 \%)$ & $94(63.9 \%)$ \\
$\begin{array}{l}\text { Previous immuno- } \\
\text { supression }\end{array}$ & $225(35 \%)$ & $15(3-11)$ & $7(2-11)$ \\
$\begin{array}{l}\text { Previous steroid } \\
\text { use }\end{array}$ & $197(30.7 \%)$ & $132(34.4 \%)$ & $16(10.9 \%)$ \\
$\begin{array}{l}\text { Mechanical } \\
\text { ventilation }\end{array}$ & $60(9.3 \%)$ & $26(6.8 \%)$ & $12(8.2 \%)$ \\
$\begin{array}{l}\text { Infection } \\
\text { Mortality }\end{array}$ & $248(38.6 \%)$ & $148(38.5 \%)$ & $51(34.7 \%)$ \\
Readmission & $59(9.2 \%)$ & $39(10.2 \%)$ & $13(8.8 \%)$ \\
\hline
\end{tabular}

Table 1B. Association between clinical factors and infection/mortality

\begin{tabular}{lll}
\hline Infection & Univariate & Multivariate \\
\hline & $\beta(95 \% \mathrm{Cl})$ & $\beta(95 \% \mathrm{Cl})$ \\
\hline Age & $1.02(1-1.02)$ & $1.02(1.01-1.03)$ \\
Use of mechanical ventilation & $4.82(1.97-11.77)$ & $4.28(1.67-10.97)$ \\
Previous use of steroids & $1.55(1.01-2.39)$ & $1.33(0.74-2.4)$ \\
Previous use of immunosupression & $1.37(0.9-2.07)$ & $1.16(0.65-2.04)$ \\
Readmission & $1.76(1.02-3.02)$ & $1.4(0.76-2.56)$ \\
Mortality & & \\
Age & $0.71(0.99-1.02)$ & $0.99(0.98-1.02)$ \\
Use of mechanical ventilation & $7.09(2.95-17.04)$ & $8.54(2.89-25.23)$ \\
Previous use of steroids & $1.95(1-3.8)$ & $0.97(0.39-2.39)$ \\
Previous use of immunosupression & $2.58(1.31-5.1)$ & $3.06(1.21-7.72)$ \\
Infection & $3.66(1.81-7.37)$ & $2.96(1.41-6.23)$ \\
Readmission & $1.33(0.58-3.05)$ & $0.42(0.14-1.24)$ \\
\end{tabular}

$\mathrm{p}<0.05$ *

Disclosure of Interests: None declared

DOI: 10.1136/annrheumdis-2021-eular.1022

\section{AB0867-HPR VIOLENCE IN PREGNANT AND POSTPARTUM MEXICAN WOMEN WITH AUTOIMMUNE RHEUMATIC DISEASES}

L. G. Espinosa Banuelos ${ }^{1}$, M. E. Corral Trujillo ${ }^{1}$, C. M. Skinner Taylor ${ }^{1}$,

L. Pérez Barbosa' ${ }^{1}$, A. Y. Lujano Negrete ${ }^{1}$, R. A. Rodriguez Chavez ${ }^{1}$

R. Moyeda Martinez ${ }^{1}$, A. Cárdenas ${ }^{1}$, D. Á. Galarza-Delgado ${ }^{1} .{ }^{1}$ Hospital

Universitario Dr. José Eleuterio González, Servicio de Reumatología,

Monterrey, Mexico

Background: Gender violence is a prevalent issue worldwide. In Mexico, four out of ten women suffer any kind of violence. The factors that make women even more vulnerable to domestic violence are pregnancy, socioeconomic status, educational level, and the presence of chronic health problems. Violence represents a major risk factor for depression, anxiety, poor adherence to medical treatment, and obstetric adverse events.

Objectives: The aim of this study is to determine the frequency of domestic violence in pregnant and postpartum women with autoimmune rheumatic diseases (ARD) and to compare with childbearing age women with ARD.

Methods: Pregnant and postpartum women (PPW) with rheumatic disease evaluated at the Pregnancy and Rheumatic Diseases Clinic from the University Hospital "Dr. José E. González" in Monterrey, México from August to October 2020 were invited to participate. To compare, we enrolled childbearing age women with ARD without previous pregnancies. The Spanish validated version of the Hurt, Insulted, Threatened with Harm, Screamed scale (HITS) was applied via telephonic interview. The HITS scale evaluates in 4 questions the presence and frequency of violence by their intimate partners in the last 12 months. A score $\geq 10$ points is considered as positive for violence.

Results: A total of 48 women were included, 24 patients each group. The pregnant-postpartum group was divided in 6 (25) pregnant and 18 (75) postpartum women. Most of them were housewives $(54.1 \%)$ with $>10$ years of education and with not formalized marital status $41 \%$ (common-law marriage). In the childbearing age group, most of them were employees (70.8), with $>10$ years of education with a current marital status of single $(66.6 \%)$. The HITS scale was positive in the pregnant-postpartum group in 4 women $(16.6 \%)$. Two of them had been victims of sexual assault and 2 reported physical/verbal violence. While in childbearing age group only 1 (4.16) reported physical/verbal violence.

Conclusion: The $16 \%$ of the pregnant-postpartum group in our sample were suffering from domestic violence by their intimate partners, in contrast to the childbearing age group with only 1 patient reported violence. We found that postpartum and pregnancy women had more prevalence of violence. Screening for domestic violence followed by counseling and early referral are necessary to mitigate the physical and psychological consequences of domestic violence. References: Moreira DN, Pinto da Costa M. The impact of the Covid-19 pandemic in the precipitation of intimate partner violence. Int $\mathrm{J}$ Law Psychiatry. 2020;71:101606. doi:10.1016/j.ijlp.2020.101606.

Jackson CL, Ciciolla L, Crnic KA, Luecken LJ, Gonzales NA, Coonrod DV. Intimate partner violence before and during pregnancy: related demographic and psychosocial factors and postpartum depressive symptoms among Mexican American women. J Interpers Violence. 2015;30(4):659-679. doi: $10.1177 / 0886260514535262$.

Table 1. Sociodemographic characteristics and scale results

\begin{tabular}{|c|c|c|}
\hline & $\begin{array}{l}\text { Postpartum and pregnancy women } \\
n=24\end{array}$ & $\begin{array}{l}\text { Childbearing age women } \\
n=24\end{array}$ \\
\hline $\begin{array}{l}\text { Age, years, mean } \\
\text { Occupation, } \mathrm{n}(\%)\end{array}$ & 27.5 & 27.08 \\
\hline Housewive & $13(54.1)$ & $5(20.8)$ \\
\hline Employee & $7(29.1)$ & $17(70.8)$ \\
\hline Student & $4(16.6)$ & $2(8.3)$ \\
\hline \multicolumn{3}{|l|}{$\begin{array}{l}\text { Education years, } \\
\mathrm{n}(\%)\end{array}$} \\
\hline Less than 10 years & $11(45.8)$ & $7(29.1)$ \\
\hline \multicolumn{2}{|l|}{ Marital status, n (\%) } & $17(70.8)$ \\
\hline $\begin{array}{l}\text { Common-law } \\
\text { marriage }\end{array}$ & $10(41.6)$ & - \\
\hline Married & $8(33.3)$ & $8(33.3)$ \\
\hline Single & $6(24.9)$ & $16(66.6)$ \\
\hline \multicolumn{3}{|l|}{ Status, n (\%) } \\
\hline Postpartum & $18(75)$ & - \\
\hline Pregnancy & $6(25)$ & - \\
\hline $\begin{array}{l}\text { Results of the HITS } \\
\text { scale }\end{array}$ & 5.37 & 4.37 \\
\hline \multicolumn{3}{|l|}{ Total, mean } \\
\hline \multicolumn{3}{|l|}{$\begin{array}{l}\text { Score per ranges, } \\
\mathrm{n}(\%)\end{array}$} \\
\hline $0-9$ points & $20(83.3)$ & $23(95.8)$ \\
\hline $10-20$ points & $4(16.6)$ & $1(4.1)$ \\
\hline
\end{tabular}




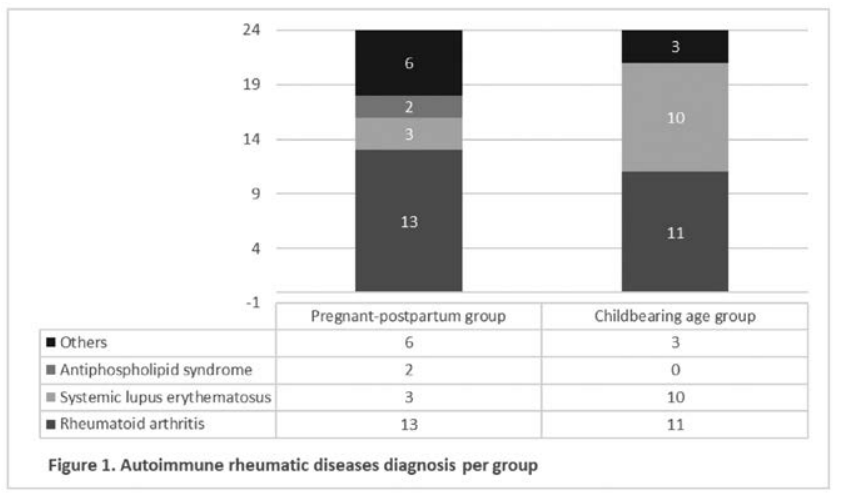

Disclosure of Interests: None declared

DOI: 10.1136/annrheumdis-2021-eular.1217

\section{AB0868-HPR ADHERENCE TO DISEASE-MODIFYING ANTIRHEUMATIC DRUGS IN RHEUMATIC DISEASES DURING COVID-19 PANDEMIC}

1. A. Moreno-Arquieta ${ }^{1}$, G. G. Sánchez Mendieta ${ }^{1}$, D. E. Flores Alvarado ${ }^{1}$, J. A. Esquivel Valerio ${ }^{1}$, D. Á. Galarza-Delgado ${ }^{1} .^{1}$ Dr. José Eleuterio González (Gonzalitos) 235, Rheumatology, Monterrey, Mexico

Background: The pandemic COVID-19 has set a new challenge in adherence to treatment in patients with rheumatic diseases. Prior studies in Latin America had reported adherence of $16.4 \%$ on Rheumatoid Arthritis (RA) and $45.9 \%$ in Systemic Lupus Erythematous (SLE). There is evidence that these patients believe their treatment increases the risk and gravity of COVID-19 and therefore, suspending the treatment could reduce this risk. It has been shown that a "Good adherence" is associated to a better survival.

Objectives: Describe the adherence to DMARDs in patients with Rheumatic diseases during COVID-19.

Methods: Descriptive, cross-sectional, self-report study conducted in rheumatology outpatient clinic of University Hospital in Monterrey, México. Consecutive patients with RA, SLE, Inflammatory Myopathies and Systemic Sclerosis, were approached during their routine appointments, March 2020 to December 2020 period during COVID-19 pandemic. They were asked how many days of the month they took the DMARD indicated in the previous appointment, with Based on this, adherence was classified into four categories: Good 100-75\% (> 21 days), Regular 74-50\% (21-15 days), Bad $49-25 \%$ (14-8 days) and Null $<25 \%$ ( $<7$ days). Data was obtained from our internal electronic patient record registry and analyzed with SPSS V.22. RESULTS:

\begin{tabular}{llllll}
\hline & $\begin{array}{c}n \\
\text { (DMARDs) }\end{array}$ & Good & Regular & Bad & Null \\
& \multicolumn{7}{c}{} & & & \\
\hline & & & & \\
\hline Rheumatoid Arthritis & 302 & $255(84.4)$ & $13(4.3)$ & $20(6.6)$ & $14(4.6)$ \\
Systemic Lupus Erithematous & 126 & $111(88)$ & $3(2.3)$ & $8(6.3)$ & $4(3.1)$ \\
Inflammatory Myopathies & 11 & $10(90.9)$ & $0(0)$ & $1(9)$ & $0(0)$ \\
Systemic Sclerosis & 30 & $27(90)$ & $2(6.6)$ & $1(3.3)$ & $0(0)$ \\
TOTAL & 469 & & & & \\
\hline
\end{tabular}

Conclusion: Despite what it is believed, patients are not changing therapeutic regimes. The adherence found in this group of patients was good, for the definition used in this study. It should be considered that the self-report method may overestimate adherence, so the data found must be correlated with objective methods in the future.

REFERENCES:

[1] Resende Prudente L, Souza Diniz J, Matteucci Ferreira TXA, Marçal Lima D, Antônio Silva N, Saraiva G, et al. Medication adherence in patients in treatment for rheumatoid arthritis and systemic lupus erythematosus in a university hospital in Brazil. Patient Preference and Adherence. 2016:10 863-870.

[2] Michaud K, Wipfler K, Shaw Y, et al. Experiences of patients with rheumatic diseases in the United States during early days of the COVID-19 pandemic. ACR Open Rheumatol 2020. doi:10.1002/acr2.11148.

[3] Waimann ChA, Marengo MF, de Achaval S, Cox VL, Garcia-Gonzalez A, Reveille JD. Electronic Monitoring of Oral Therapies in Ethnically Diverse and Economically Disadvantaged Patients With Rheumatoid Arthritis. Arthritis \& Rheumatism. 2013:6 1421-1429.

Disclosure of Interests: None declared

DOI: 10.1136/annrheumdis-2021-eular.2131

\section{AB0869-HPR \\ HOW TO IMPROVE THE QUALITY-OF-LIFE IN PATIENTS} WITH OSTEOPOROSIS?

A. Lammert ${ }^{1}$, S. Lezhenina ${ }^{1}$, N. Shuvalova ${ }^{2}$, N. Andreeva ${ }^{1}$, E. Guryanova ${ }^{3} .{ }^{1} I . N$. Ulianov Chuvash State University, Departament of Healthcare Management and Economics, Cheboksary, Russian Federation; ${ }^{2}$ I. Ya. Yakovlev Chuvash Pedagogical State University, Department, Cheboksary, Russian Federation;

${ }^{3}$ I. N. Ulianov Chuvash State University, Department Internal Diseases, Cheboksary, Russian Federation

Background: This paper is an assessment of quality-of-life for patients living with osteoporosis. It employs special questionnaires and scales to allow for more detailed observation of the patient both during initial treatment and in dynamics. This allows us to establish the effectiveness of the therapy, to assess the need to correct the treatment and rehabilitation program, and to compare the effectiveness of various treatment methods and determine disease prognosis.

Objectives: to assess quality-of-life in patients with osteoporosis for further development of treatment and rehabilitation programs.

Methods: To assess the quality-of-life in patients with osteoporosis, HRQOL and SF-36 scale were used. The study was conducted from January to December 2019, at the Republican Clinical Hospital of the Chuvash Republic. The study involved 70 patients $(n=70)$ with a diagnosis of osteoporosis with a pathological fracture. Of the 70 patients included in the study, 35 women aged $67 \pm 1.2$ years and 35 men aged $60 \pm 1.2$ years. The results were statistically processed using MS Office Excel programs.

Results: According to the analysis carried out by the HRQOL method, more than half of the patients $(52.13 \%)$ experienced daily back pain, which worsens their mood and well-being. When assessing the degree of pain, almost half of the patients $(48.73 \%)$ rated their pain by VAS as moderate. Moreover, most of the respondents experienced a "significant" $(46.51 \%)$ or "moderate" $(34.29 \%)$ decrease in social activity due to pain syndrome associated with osteoporosis. In connection with this, $44.51 \%$ rated their satisfaction with their lives as "average degree of satisfaction".

When analyzing the quality-of-life indicators according to the SF-36 scales, we determined that the mental component of health predominates for women (The Short Form-36: $\mathrm{MH}=68,6 \pm 3,45$ (Men: $\mathrm{MH}=48,5 \pm 2,85)$ ). In men, high quantitative values of the scales "physical" and "role physical functioning" (The Shor Form-36: $\mathrm{PF}=62,5 \pm 3,33 ; \mathrm{RP}=58,4 \pm 3,81$ ) indicate a more pronounced nature of changes in somatic status, which has a significant impact on the quality-of-life The intensity of pain was perceived to be higher by men (The Short Form-36: $\mathrm{BP}=75,6 \pm 4,06$ ) than by women (The Short Form-36: $\mathrm{BP}=35,7 \pm 1,86$ ). This confirms that osteoporosis and its complications negatively affect the human psyche and can significantly worsen the quality-of-life.

Conclusion: Analysis of quality-of-life indicators using the SF-36, HRQOL method contributes to a more correct choice of effective strategy for specialized medical care and rehabilitation for patients with osteoporosis. This choice should be developed individually, taking into account the age, gender characteristics, the severity of structural and functional disorders and the psychological state of the patient. It must also take into account the presence and severity of concomitant diseases, which will require additional research and discussion at different levels of the organization of medical care.

Disclosure of Interests: None declared

DOI: 10.1136/annrheumdis-2021-eular.2160

\section{AB0870-HPR GLOBAL TRENDS IN PRP AND OSTEOARTHRITIS: A BIBLIOMETRIC AND VISUALIZED STUDY}

Y. Qiu ${ }^{1}$, Y. Zhang ${ }^{1}$, L. Wen ${ }^{1} .{ }^{1}$ Beijing Hospital, National Center of Gerontology, Deparment of Orthopedic, Beijing, China

Background: Osteoarthritis $(O A)$ is a serious disease, which is one of the main causes of joint pain and body dysfunction, raising serious economic and social burden. In recent years, there are tremendous articles on the treatment of osteoarthritis, platelet rich plasma (PRP) is one of the new trends in the treatment of osteoarthritis.

Objectives: The purpose of this study is to explore the development trend of PRP related osteoarthritis study and grasp the hot spots and directions in this field.

Methods: Publications focusing on PRP related osteoarthritis research from 2001 to 2020 were retrieved from Web of Science (WoS) and Science Citation Index-Expanded (SCIE) database. The retrieving methods were as follow: (theme = platelet rich plasma arthritis OR theme = platelet rich plasma osteoarthritis OR theme $=$ platelet rich plasma cartilage $\mathrm{OR}$ theme $=$ platelet rich plasma knee $\mathrm{OR}$ theme = platelet rich plasma orthopedic OR theme = platelet rich plasma orthopaedic $\mathrm{OR}$ theme $=$ platelet rich plasma articular $\mathrm{OR}$ theme $=$ platelet rich plasma joint $\mathrm{OR}$ theme = platelet rich plasma tendon). Publications were analyzed only when type is articles or reviews. The VOS viewer was used for the generation of bibliographic coupling and visualized study. 